\title{
Effects of Technological, Organizational, and Environmental Factors on Social Media Adoption*
}

\author{
Sikandar Ali QALATI ${ }^{1}$, Wenyuan LI $^{2}$, Esthela Galvan VELA ${ }^{3}$, \\ Ali BUX ${ }^{4}$, Belem BARBOSA ${ }^{5}$, Ahmed Muhammad HERZALLAH ${ }^{6}$
}

Received: July 25, 2020 Revised: August 23, 2020 Accepted: September 05, 2020

\begin{abstract}
Electronic commerce is becoming a significant hub for sourcing products/services which helps organizations to connect with potential customers and gain competitive advantages, though little empirical work focuses on small businesses operating in developing countries to date. Increasingly, companies are looking to utilize social media to connect with stakeholders and pursue several benefits. This study aims to investigate the technological, organizational, and environmental (TOE) factors that influence small- and medium-sized enterprises' (SMEs) social media (SM) adoption in developing countries. This study used a closed-ended questionnaire to collect data from randomlyselected respondents (owners, executives, and managers) from SMEs in Pakistan. SMART PLS version 3.2.8 was used for path analysis of 316 responses and for structural equation modeling. The research findings include the direct influence of TOE factors (relative advantage, interactivity, visibility, top management support, and institutional pressure) on SMEs' SM adoption, and in turn SM adoption also has a positive influence on SMEs performance. Moreover, the coefficient of determination of the study showed that $77.7 \%$ of the variation in SM adoption occurs because of TOE factors and 29.8\% variation in SMEs occurred because of SM adoption. This paper has implications for practitioners and scholars interested in exploring the SM adoption and usage by SMEs.
\end{abstract}

Keywords: Small and Medium-Sized Enterprises, Developing Countries, Social Media Adoption, Institutional Pressure, Relative Advantage

JEL Classification Code: M37, O33

\section{Introduction}

\footnotetext{
*Acknowledgements:

This study was supported by the National Social Science Fund of China (15BGL032)

${ }^{1}$ First Author. School of Management, Jiangsu University, P.R. China [Postal Address: 301 Xuefu Road, Jingkou District, Zhenjiang, Jiangsu Province, China] Email: 5103180243@stmail.ujs.edu.cn

${ }^{2}$ School of Management, Jiangsu University, P.R. China.

Email: liwenyuan8@stmail.ujs.edu.cn

${ }^{3}$ CETYS Universidad, Escuela de Administracion y Negocios Campus, Tijuana, México. Email: esthela.galvan@cetys.mx

${ }^{4}$ Corresponding Author. IT Department, Sukkur IBA University,

Pakistan [Postal Address: Airport Road, Sukkur District, Sindh

Province, 65200, Pakistan] Email: ali.bux@iba-suk.edu.pk

${ }^{5} \mathrm{Higher}$ Institute of Accounting and Administration (ISCA-UA), University of Aveiro, Portugal. Email: marketing.belem@gmail.com ${ }^{6}$ Department of Business Administration, Al-Quds University, Palestine. Email:ahizrallah@staff.alquds.edu

(c) Copyright: The Author(s)

This is an Open Access article distributed under the terms of the Creative Commons Attribution Non-Commercial License (https://creativecommons.org/licenses/by-nc/4.0/) which permits unrestricted non-commercial use, distribution, and reproduction in any medium, provided the original work is properly cited.
}

In the present era of globalization, technology is considered a key factor for improving market competitiveness and the country's economic situation. Generally, large organizations seized on opportunities to pursue and achieve economies of scale due to sufficient resources. And small businesses always suffered because of the limited resources, but technological development plays a key role in making small- and medium-sized enterprises (SMEs) competitive and enables them to be sustainable. Therefore, it is essential to focus on the factors that influence the adoption of technologies (Das et al., 2020). Ahmad et al. (2018) argued that technology, like social media (SM), could easily be adopted by a large organization because it is already connected to the Internet. But SM can be used by SMEs because of the minimal technical requirements and cost-effectiveness. The company can use SM for organizational public relations and communications, which help them to understand consumers' needs and drive them to react proactively and effectively to those needs (Parveen et al., 2016). Besides, Nguyen and Luu (2020) identified the several factors influencing the adoption by 
industry and argued that there are limited studies dedicated to developing countries. The success of any technology and its influences on firm performance necessitates being appropriately adopted by firms. As many firms invest in $\mathrm{SM}$, it is critical to identify the drivers that are linked with the adoption of technologies. Moreover, the adoption of new media like SM has significantly shifted marketing strategy and focus, and SM is now considered an important element of a marketing strategy (Becker \& Lee, 2019).

Prior studies showed that the technological, organizational, and environmental (TOE) framework had been a prevalent model in exploring several information system issues. Empirical findings that employed the TOE model in the context of SMEs confirmed that it is an appropriate framework that can be used to understand the technology-based adoption (Ahmad et al., 2018; Cao et al., 2018). Unlike other technology, SM is a highly open and publicly-oriented system, which has both pros and cons. Thus, there may be other TOE determinants that are more specific to SM, which might influence SM adoption by SMEs. Therefore, to fill this gap in the existing literature and to advance the overarching model that defines the antecedents and advantages of SM adoption, we employed TOE framework.

This research aims to investigate the factors linked with TOE that help the SM adoption by SMEs, though the degree to which SM benefits SMEs is still not clear. Few studies have investigated the use of SM to advance business practices and their effects on organizations' performance (Garg et al., 2020). Though past studies explored the effects of SM on SMEs, several areas remains unexplored, including antecedents of SMEs success, the use of digital platforms by SMEs, and the effects on SMEs survival (Olanrewaju et al., 2020). Thus, this study investigates the factors of SM adoption in SMEs mainly operating in developing countries.

\section{Literature Review}

\subsection{Theoretical Background and Conceptual Development}

Unlike existing work, Chatterjee and Kar (2020), Lee et al. (2016) and Wamba et al. (2017) used linear models with a technology acceptance model or united theory of acceptance and use of technology. Wong et al. (2020) argue that they ignore organizational and environmental factors. The TOE framework comprises three different context groups - technological, organizational, environmental. The technological context refers to both current and new technologies that are applicable to the organization. The organizational context refers to the features of the firm in terms of its size, managerial level, and scope. The environmental context refers to the environment in which firms operate, referring to its competitors, government agencies, and the industry. Indeed, as the TOE framework is combining both human and non-human determinants into a single framework, this provides superior strength over traditional models such as technology acceptance model and united theory of acceptance and use of technology (Awa et al., 2017). Many papers have linked new technology adoption with the TOE dimensions of the firm and provided a bigger sketch of the drivers influencing technology adoption (Abed, 2020).

The empirical findings from research adopting the TOE model have ensured that it is a valuable model with which to comprehend the IT-based adoption of innovation, especially SM by SMEs (Tajudeen et al., 2018). In addition, based on Abed (2020) argument that very little empirical work has been dedicated to SMEs to date regarding SM adoption, he concludes that the TOE framework has a robust theoretical basis, strong empirical support, and has been employed to investigate the adoption of new SM technology. The TOE framework is consistent with the contingency theory, resource-based view theory, and diffusion of innovation theory (Ahmad et al., 2018). This study employed some of the general TOE factors and also included specific drivers that are unique to SM and explored their influence on SM adoption (refer Figure 1)

\subsection{Hypothesis Development}

\subsubsection{Technological Characteristics and SM Adoption}

This study used three characteristics - relative advantage, interactivity, and visibility - of technology to be adopted. The relative advantage is the extent to which potential adopters consider innovation better than the alternative. Pee (2018) stated that awareness of the relative advantage of the enterprises' SM is beneficial to improve knowledge sharing and overall organization performance. Interactivity is the extent to which two or more parties can interact with each other using technology. SM is an innovative technology as it provides ways to increase the interaction between customers and organizations (Kizgin et al., 2020). Visibility is the extent to which something attracts general attention. Due to limited resources, SMEs are required to use and leverage SM for marketing activities as it provides them more visibility in contrast to large organizations (Braojos-Gomez et al., 2015). Past studies largely focus on the relative advantage, compatibility, and cost-effectiveness as predecessors of the technology adoption (Olanrewaju et al., 2020). Cesaroni and Consoli (2015) argue that the adoption of SM and its usage can provide organizations with higher visibility, interactivity, and cost-effectiveness. Thus, we proposed the following hypotheses: 


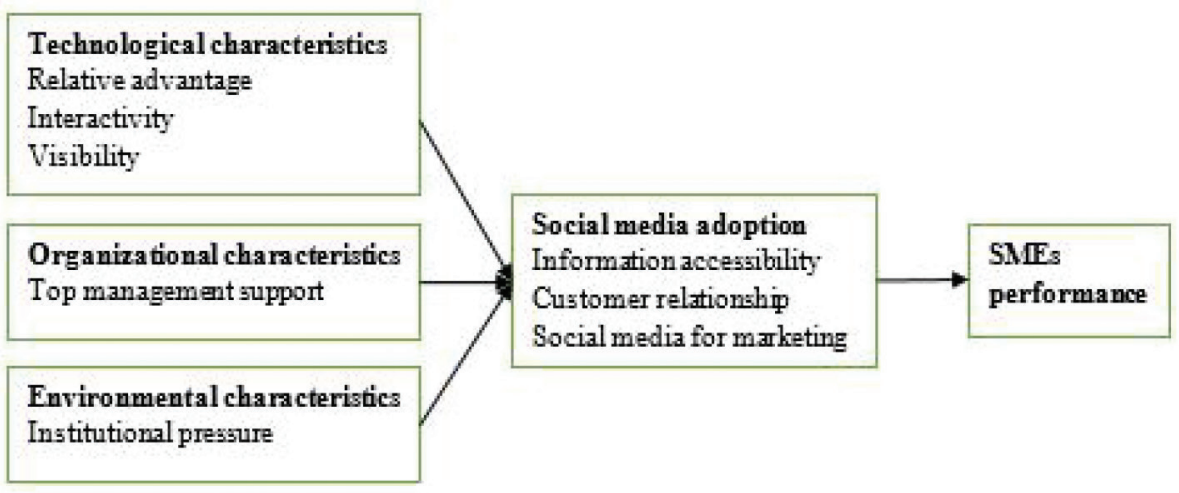

Figure 1: Conceptual framework

H1. Relative advantage have a significant influence on SM adoption in SMES

H2. Interactivity has a significant influence on SM adoption in SMEs

H3. Visibility has a significant influence on SM adoption in SMEs

\subsubsection{Organizational characteristic and SM Adoption}

The organizational construct includes internal characteristics of firms such as number of employees, size, turnover, managerial structure, and related issues. This study used top management and entrepreneurial orientation characteristics. The existing literature grounded on innovation largely focuses on top management as the main factor for varying the norms, values, and culture within the firms; in turn, this allows other internal stakeholders to adapt to the new technology (Olanrewaju et al., 2020). SM provides not only the advantages, but also disadvantages, which hinder top management choice to adopt SM. Some of the negative sides of SM adoption include the employees' waste of time and negative posts from dissatisfied customers, which can affect organization reputation (Ahmad et al., 2018). Furthermore, SM adoption requires continuous monitoring and well-educated and trained staff (Tajudeen et al., 2018). Maduku et al. (2016) found a significant relationship between top management support and mobile marketing adoption intention in African SMEs. Therefore, we hypothesize the following:

H4. Top management support has a significant influence on SM adoption in SMEs

\subsubsection{Environmental Characteristics}

This study used institutional pressure as a key factor in environmental characteristics. The institutional theory was found to be relevant in this research. This theory states that environmental factors like institutional pressures drive firms to adopt innovations (Henderson et al., 2012). The institutional pressure defines the pressure that comes from the external environment that can persuade organizations to adopt general practices (DiMaggio \& Powell, 1983). The stakeholders that may pressurize the firms to adopt SM includes potential customers, government agencies, and competitors. Past studies also used an institutional approach to investigate SM usage (Tajudeen et al., 2018). Thus, we proposed the following hypothesis:

H5. Institutional pressure has a significant influence on SM adoption in SMEs

\subsubsection{Social Media Adoption and SMEs Performance}

SM is a place for emotional expression, social activism, two-way communication, friendship development, and news updating. From an individual perspective, it is an e-space to share photos, update daily information, and drive a sense of belonging and self assurance (Nguyen, 2018). Whereas from an organizational viewpoint little is known. This study also investigated the influence of SM adoption on SMEs. The past scholarship outlined the importance of SM adoption in improving firm performance (Abu Bakar et al., 2019; Garg et al., 2020) and also it tested the association between SM and firm performance. The organizational usage of SM (Facebook) has an impact by improving customer relationships, information accessibility, and marketing (Ainin et al., 2015). Muafi (2020) argued that SM network offers a platform for knowledge sharing, innovation, and enhancement of SMEs' performance. Also, it improves the productivity of SMEs and increases their competitiveness (Potluri \& Vajjhala, 2018). Moreover, with the growing expansion of social networking sites, it is important for all sizes of firms to protect the reputation of organization and brands. Thus, it is essential for the companies to adopt SM to improve reputation (Lee \& Kwag, 2017). Olanrewaju et al. (2020) suggested that the SM adoption-SME performance link should be investigated in a more holistic manner using 
a longitudinal approach. Therefore, the current study aims to provide more robust empirical evidence by using a time-lag approach. In summary, we hypothesize:

H6. SM adoption has a significant influence on SMEs' performance.

\section{Methodology}

\subsection{Sample and Data Collection}

The critical respondents targeted were owners, executives, and managers, as they were considered to be the most well-informed about the organization's performance and environment (Zieba et al., 2016). A closed-ended questionnaire was used for data collection. Data collection occurred from May 2019 to October 2019 in the four regions of Pakistan - Sindh, Punjab, Baluchistan, and Khyber Pakhtunkhwa. The reason for collecting data in six months' lag time was to mitigate common method bias (Khan et al., 2019). In total, 316 valid responses were used for the analysis.

\subsection{Measures}

The five-point Likert scale ( $1=$ " strongly disagree"; $5=$ "strongly agree") was used to record responses. The technological construct was assessed as follows: relative advantage - seven items were adapted from Ahmad et al. (2018); interactivity - three items were adapted from Ainin et al. (2015); visibility - three items were adapted from Dutot and Bergeron (2016). The top management support was assessed using four items from Ahmad et al. (2019). The institutional pressure was measured by adapting six items from Tajudeen et al. (2018). Specifically, SM adoption was assessed using 13 items - marketing (four items), customer relations and services (six items), and information accessibility (three items) adapted from Parveen et al. (2016). SMEs' performance was assessed using seven items from Cao et al. (2018) and Parveen et al. (2016).

\section{Results and Discussion}

\subsection{Respondents and SMEs Information}

Table 1 shows that, out of 316 respondents, 230 (72.7\%) were male and $86(27.3 \%)$ were female. Most respondents $110(34.8 \%)$ were aged between 26 and 35 and had a master's degree 143 (45.2\%). Thus, most decision-makers were young and well-educated. The majority of respondents were managers (41.8\%), followed by executives (34.8\%). Regarding company size, 176(55.7\%) had between 11 and 50 employees. The sample contained firms from diverse sectors, including businessrelated firms, professional services providers, information and communication technologies, restaurants and event organizers, and logistics; most of them 147 (46.5\%) were business-related. Regarding SM usage, 132 (41.7\%) respondents admitted that SM use was minimal, reflecting a lack of interest, trust, and technical knowledge. However, the extensive use of SM as a marketing tool was revealed by other results for SM adoption ["A lot", 116 (36.7\%); and "Extensive", 113 (35.7\%)]. Regarding budget allocation, most respondents (284) allocate less than 25\% to SM. Most SMEs 139 (44.0\%)] were operating in Sindh, and 110 (34.8\%) were using Facebook.

This study employed partial least square structural equation modeling to test the hypothesize model given its widespread application in business management and related disciplines, and it is considered the most fully developed and comprehensive system of variance. This study employs the full collinearity approach, specifically the variance inflation factor (VIF) for detecting evidence on common method bias (CMB) (Ahmed et al., 2020). The results of the study (Table 2) show that CMB is not a key concern since the computed VIFs are less than 5 (Hair et al., 2011). This study used a twostep approach evaluation of the measurement model and the structural model (Hair et al., 2010; Tian et al., 2020).

\subsection{Evaluation of Measurement Model}

At first, data were analyzed by assessing the central tendency and dispersion, followed by measuring validity and reliability (refer to Table 2). The reliability of the scales was measured using Cronbach's alpha (CA). According to Nunnally (1978), the CA values should exceed 0.7. After that, principle components analysis on each item was conducted. Afterward, convergent validity was projected (Li et al., 2020). Internal consistency reliability requires composite reliability (CR) to be $\geq 0.7$ (Qalati et al., 2020). Regarding convergent validity, Fornell and Larcker (1981) recommended that the average variance extracted (AVE) should be $\geq 0.5$ (Table 2). Table 2 shows the item loadings, weights, p-values, CA, $\mathrm{CR}, \mathrm{AVE}$, and Inner VIF to assess the reliabilities, internal consistency, convergent validity, and common method bias.

Regarding discriminant validity (see Table 3 ), the square of AVE for each variable must exceed the inter-correlation of the variables (Fornell \& Larcker, 1981).

\subsection{Evaluation of Structural Model}

According to Wong (2013), the structural model should be used to assess the linear regression effects of the dependent variables on one another. This paper used PLS bootstrapping with 5000 bootstraps and 316 cases for demonstration of results related to paths and their significance level. Table 4 presents the comprehensive evaluations from the structural model. Figure 2 also illustrates the path coefficients and their level of significance. 
Table 1: Demographical statistics of respondents and SMEs'.

\begin{tabular}{|c|c|c|c|}
\hline & & Frequency & Percentage \\
\hline \multirow[t]{2}{*}{ Gender } & Male & 230 & 72.7 \\
\hline & Female & 86 & 27.3 \\
\hline \multirow[t]{4}{*}{ Age (years) } & Less than 25 & 36 & 11.4 \\
\hline & $26-35$ & 110 & 34.8 \\
\hline & $36-45$ & 94 & 29.7 \\
\hline & Over 50 & 76 & 24.0 \\
\hline \multirow[t]{4}{*}{ Education } & Basic/secondary & 13 & 4.1 \\
\hline & Undergraduate & 99 & 31.4 \\
\hline & Master's & 143 & 45.2 \\
\hline & Other & 61 & 19.3 \\
\hline \multirow[t]{3}{*}{ Position } & Owner & 74 & 23.4 \\
\hline & Executive & 110 & 34.8 \\
\hline & Manager & 132 & 41.8 \\
\hline \multirow[t]{3}{*}{ No. of employees } & Less than 10 & 58 & 18.3 \\
\hline & $11-50$ & 176 & 55.7 \\
\hline & $51-250$ & 82 & 26.0 \\
\hline \multicolumn{4}{|l|}{ Demographical statistics of SMEs' } \\
\hline \multirow[t]{5}{*}{ Industry sector } & Business-related (manufacturing, services, construction) & 147 & 46.5 \\
\hline & Professional services & 45 & 14.2 \\
\hline & ICT & 71 & 22.5 \\
\hline & Restaurants and events & 32 & 10.0 \\
\hline & Logistics & 21 & 6.7 \\
\hline \multirow[t]{4}{*}{$\begin{array}{l}\text { Firms level of utilization of social } \\
\text { media }\end{array}$} & Minimum & 132 & 41.7 \\
\hline & Basic & 104 & 33.0 \\
\hline & Moderate & 55 & 17.3 \\
\hline & Extensive & 25 & 8.0 \\
\hline \multirow[t]{4}{*}{ Use of SM as a marketing tool } & Minimal & 57 & 18.0 \\
\hline & Little & 30 & 9.5 \\
\hline & A lot & 116 & 36.7 \\
\hline & Extensive & 113 & 35.8 \\
\hline \multirow[t]{3}{*}{ Budget allocated } & Less than $25 \%$ & 284 & 90.0 \\
\hline & $26-50 \%$ & 17 & 5.3 \\
\hline & Over $50 \%$ & 15 & 4.7 \\
\hline \multirow[t]{4}{*}{ Location of the business } & Sindh & 139 & 44.0 \\
\hline & Baluchistan & 37 & 11.7 \\
\hline & Punjab & 92 & 29.1 \\
\hline & Khyber Pakhtunkhwa & 48 & 15.2 \\
\hline \multirow[t]{5}{*}{ Social media platform used } & Facebook & 110 & 34.8 \\
\hline & Twitter & 18 & 5.7 \\
\hline & Linkedln & 62 & 19.6 \\
\hline & WhatsApp & 92 & 29.1 \\
\hline & YouTube and other & 34 & 10.8 \\
\hline
\end{tabular}


Table 2: Evaluation of measurement model

\begin{tabular}{|c|c|c|c|c|c|c|}
\hline & Item code & Loadings & CA & CR & AVE & VIF \\
\hline Relative & RA1 & 0.766 & 0.952 & 0.961 & 0.778 & 2.851 \\
\hline \multirow[t]{6}{*}{ advantage } & RA2 & 0.872 & & & & \\
\hline & RA3 & 0.913 & & & & \\
\hline & RA4 & 0.900 & & & & \\
\hline & RA5 & 0.915 & & & & \\
\hline & RA6 & 0.913 & & & & \\
\hline & RA7 & 0.886 & & & & \\
\hline \multirow[t]{3}{*}{ Interactivity } & 11 & 0.911 & 0.868 & 0.919 & 0.791 & 2.71 \\
\hline & 12 & 0.871 & & & & \\
\hline & 13 & 0.886 & & & & \\
\hline \multirow[t]{3}{*}{ Visibility } & V1 & 0.925 & 0.906 & 0.941 & 0.842 & 2.604 \\
\hline & $\mathrm{V} 2$ & 0.918 & & & & \\
\hline & V3 & 0.910 & & & & \\
\hline Top management & TMS1 & 0.917 & 0.935 & 0.954 & 0.837 & 1.992 \\
\hline \multirow[t]{3}{*}{ support } & TMS2 & 0.919 & & & & \\
\hline & TMS3 & 0.911 & & & & \\
\hline & TMS4 & 0.914 & & & & \\
\hline Institutional & IP1 & 0.801 & 0.873 & 0.904 & 0.612 & 2.110 \\
\hline \multirow[t]{5}{*}{ pressure } & IP2 & 0.785 & & & & \\
\hline & IP3 & 0.795 & & & & \\
\hline & IP4 & 0.717 & & & & \\
\hline & IP5 & 0.796 & & & & \\
\hline & IP6 & 0.796 & & & & \\
\hline Social media adoption & & & 0.948 & 0.955 & 0.618 & 1 \\
\hline Customer & CR1 & 0.745 & 0.888 & 0.915 & 0.642 & \\
\hline \multirow[t]{5}{*}{ relationship } & CR2 & 0.725 & & & & \\
\hline & CR3 & 0.772 & & & & \\
\hline & CR4 & 0.813 & & & & \\
\hline & CR5 & 0.754 & & & & \\
\hline & CR6 & 0.726 & & & & \\
\hline Information & IA1 & 0.800 & 0.961 & 0.974 & 0.927 & \\
\hline \multirow[t]{2}{*}{ accessibility } & IA2 & 0.811 & & & & \\
\hline & IA3 & 0.822 & & & & \\
\hline Social media & SMM1 & 0.812 & 0.944 & 0.959 & 0.855 & \\
\hline \multirow[t]{3}{*}{ marketing } & SMM2 & 0.811 & & & & \\
\hline & SMM3 & 0.822 & & & & \\
\hline & SMM4 & 0.797 & & & & \\
\hline SMEs' & $\mathrm{P} 1$ & 0.831 & 0.935 & 0.947 & 0.718 & \\
\hline \multirow[t]{6}{*}{ performance } & $\mathrm{P} 2$ & 0.875 & & & & \\
\hline & P3 & 0.862 & & & & \\
\hline & $\mathrm{P} 4$ & 0.839 & & & & \\
\hline & P5 & 0.861 & & & & \\
\hline & P6 & 0.843 & & & & \\
\hline & P7 & 0.819 & & & & \\
\hline
\end{tabular}


Table 3: Discriminant validity.

\begin{tabular}{|l|c|c|c|c|c|c|c|}
\hline & $\mathbf{1}$ & $\mathbf{2}$ & $\mathbf{3}$ & $\mathbf{4}$ & $\mathbf{5}$ & $\mathbf{6}$ & $\mathbf{7}$ \\
\hline Institutional pressure & 0.782 & & & & & & \\
\hline Interactivity & 0.581 & 0.89 & & & & & \\
\hline Relative advantage & 0.619 & 0.748 & 0.882 & & & & \\
\hline SMEs' performance & 0.489 & 0.461 & 0.457 & 0.848 & & & \\
\hline Social media adoption & 0.688 & 0.719 & 0.74 & 0.546 & 0.786 & & \\
\hline Top management support & 0.624 & 0.603 & 0.595 & 0.478 & 0.777 & 0.915 & \\
\hline Visibility & 0.645 & 0.694 & 0.709 & 0.464 & 0.757 & 0.601 & 0.918 \\
\hline
\end{tabular}

Note: * Values on the diagonal (bold and italic) are the square root of the AVE while the off-diagonals are correlations

Table 4: Path coefficient and hypotheses testing.

\begin{tabular}{|c|l|c|c|c|c|}
\hline Hypothesis & \multicolumn{1}{|c|}{ Relationship } & Path coefficient & SD & t-value & Decision \\
\hline H1 & Relative advantage $\rightarrow$ SM adoption & 0.183 & 0.053 & $3.472^{* *}$ & Supported \\
\hline H2 & Interactivity $\rightarrow$ SM adoption & 0.118 & 0.047 & $2.492^{* * *}$ & Supported \\
\hline H3 & Visibility $\rightarrow$ SM adoption & 0.245 & 0.064 & $3.807^{* *}$ & Supported \\
\hline H4 & Top management support $\rightarrow$ SM adoption & 0.381 & 0.075 & $5.067^{* *}$ & Supported \\
\hline H5 & Institutional pressure $\rightarrow$ SM adoption & 0.111 & 0.055 & $2.011^{* * *}$ & Supported \\
\hline H6 & SM adoption $\rightarrow$ SMEs' performance & 0.546 & 0.054 & $10.105^{* *}$ & Supported \\
\hline
\end{tabular}

Note: Critical values. ${ }^{* *}$ t-value $>2.58(p<0.01),{ }^{* *}$ t-value $>1.96(p<0.05)$

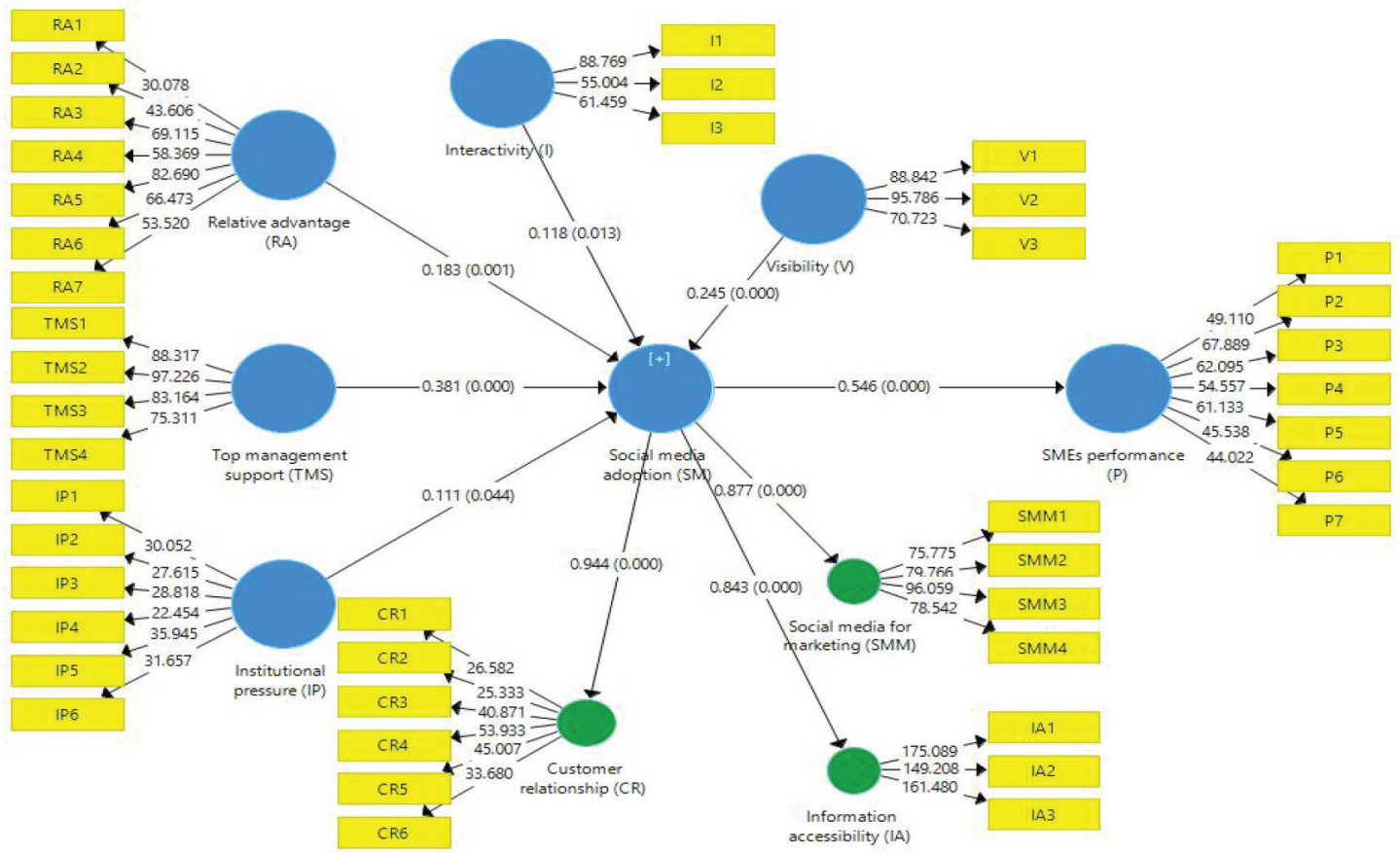

Figure 2: Structural equation modeling 
Table 5: Structural model.

\begin{tabular}{|l|c|c|c|c|c|c|}
\hline & \multicolumn{3}{|c|}{ Cross validated redundancy } & \multicolumn{2}{c|}{ Coefficient of determination } & SRMR \\
\hline Construct & SSO & SSE & $\mathrm{Q}^{2}(=1-$ SSE/SSO $)$ & $\mathrm{R}^{2}$ & Adj. $\mathrm{R}^{2}$ & \\
\cline { 1 - 6 } SM adoption & $4,108.00$ & $2,278.648$ & 0.445 & 0.777 & 0.774 & \multirow{2}{*}{0.070} \\
\cline { 1 - 6 } SMEs' performance & $2,212.00$ & $1,778.944$ & 0.196 & 0.298 & 0.295 & \\
\hline
\end{tabular}

According to Cohen (1988), $\mathrm{R}^{2}$ values of $0.60,0.33$, and 0.19 are, respectively, substantial, moderate, and weak. In the present study, the $\mathrm{R}^{2}$ value of 0.777 indicates that $77.7 \%$ of the variation in SM adoption occurred because of TOE factors, while $29.8 \%$ of the variation in SMEs' performance occurred because of SM adoption (refer Table 5). In addition, this study employed the cross-validated redundancy measure $\left(Q^{2}\right)$ to evaluate the model. Henseler et al. (2009) suggested that $\mathrm{q}^{2}>0$ shows that the model has predictive relevance. Values of $0.02,0.15$, and 0.35 , respectively, indicate that an exogenous construct has a small, medium, or considerable predictive relevance for a specific endogenous construct. The current study's model has considerable predictive relevance for SM adoption and medium predictive relevance for SMEs' performance (Table 5).

Hair et al. (2011) propose the standardized root means square residual (SRMR) to assess the goodness of fit. SRMR is an absolute measure of fit: a value of zero indicates perfect fit, and a value less than 0.08 is considered a good fit ( $\mathrm{Hu} \&$ Bentler, 1999). Table 5 demonstrates the study's adequate goodness of fit.

This study highlights a number of TOE factors influencing SMEs' social media adoption. The results of the study interestingly stated that the relative advantage is found to be relevant in SMEs SM adoption decision $(p=0.001)$; thus, $\mathrm{H} 1$ is supported. These findings are consistent with Ainin et al. (2015). The interactivity of SM adoption is considered a vital factor ( $p=0.013)$; therefore, $\mathrm{H} 2$ is supported. The results imply that SM offers an interactive platform that enable SMEs to have two-way communication with customers and business partners, which encourages enterprises to adopt it. These findings are in line with Alalwan (2018). Due to limited resources, visibility is also found significant for SMEs ( $p=0.001$ ); thus, $\mathrm{H} 3$ is supported. These findings are consistent with Braojos-Gomez et al. (2015).

Top management support was found to be one of the essential factors in SMEs' decision to adopt SM $(p=0.001)$; hence, H4 is supported. This finding is consistent with Ahmad et al. (2019). The results suggest that top management is keen on SM adoption and that employees are required to use SM extensively as a marketing tool. Another significant factor of SMEs SM adoption was institutional pressure $(p=0.044)$; hence, H5 is supported. The results imply that pressure from the external environment has a positive influence on SM adoption. These findings are consistent with previous research, which argued that institutional pressure is one of the key factors of technology adoption (Tajudeen et al., 2018).

Lastly, the result of the study also demonstrates that SM adoption and usage have the strongest effects on SMEs' performance (bets $=0.55, \mathrm{p}=0.001$ ) in terms of improving customer and service quality, cost reduction, and enhance information accessibility. Thus, H6 is supported. This result is found to be consistent with Cao et al. (2018 and Parveen et al. (2016).

\section{Conclusion}

This study investigated the impacts of SM adoption on SMEs' performance in developing countries, specifically Pakistan. The findings suggest that SM has a significant effect on SMEs' performance. Despite this substantial impact, budget allocation remains less than $25 \%$. Furthermore, $41.7 \%$ of SMEs studied only used SM minimally for marketing. This paper suggests that SM enables SMEs operating in developing countries to connect effectively with customers, business partners, and other stakeholders on a more personal level because SM facilitates direct communications and immediate replies. Most importantly, this work highlights that SM adoption allows SMEs to build brand awareness and loyalty, improve customer relationships, and provide several benefits, including cost-effectiveness, relative advantage, visibility, and interactivity so that they can adjust to market conditions with limited resources. Ultimately, the proposed constructs provide a more detailed understanding of SM adoption for SME decision-makers.

\section{References}

Abed, S. S. (2020). Social commerce adoption using TOE framework: An empirical investigation of Saudi Arabian SMEs. International Journal of Information Management, 53, 102-118. doi:https://doi.org/10.1016/j.ijinfomgt.2020.102118

Abu Bakar, A. R., Ahmad, S. Z., \& Ahmad, N. (2019). SME social media use: A study of predictive factors in the United Arab Emirates. Global Business and Organizational Excellence, 38(5), 53-68. https://doi.org/10.1002/joe.21951

Ahmad, S. Z., Bakar, A. R. A., \& Ahmad, N. (2018). Social media adoption and its impact on firm performance: the case of the UAE. International Journal of Entrepreneurial Behavior \& Research, 25(1), 84-111. https://doi.org/10.1108/IJEBR-08-2017-0299 
Ahmad, S. Z., Bakar, A. R. A., \& Ahmad, N. (2019). Social media adoption and its impact on firm performance: the case of the UAE. International Journal of Entrepreneurial Behavior \& Research, 25(1), 84-111. https://doi.org/10.1108/ IJEBR-08-2017-0299

Ahmed, N., Li, C., Qalati, S. A., Rehman, H. u., Khan, A., \& Rana, F. (2020). Impact of Business Incubators on Sustainable Entrepreneurship Growth with Mediation Effect. Entrepreneurship Research Journal. [In Press] https://doi. org/10.1515/erj-2019-0116

Ainin, S., Parveen, F., Moghavvemi, S., Jaafar, N. I., \& Shuib, N. L. M. (2015). Factors influencing the use of social media by SMEs and its performance outcomes. Industrial Management \& Data Systems, 115(3), 570-588. https://doi.org/10.1108/ IMDS-07-2014-0205

Alalwan, A. A. (2018). Investigating the impact of social media advertising features on customer purchase intention. International Journal of Information Management, 42, 65-77. https://doi.org/10.1016/j.ijinfomgt.2018.06.001

Awa, H. O., Uko, J. P., \& Ukoha, O. (2017). An empirical study of some critical adoption factors of ERP software. International Journal of Human-Computer Interaction, 33(8), 609-622. https://doi.org/10.1080/10447318.2016.1265828

Becker, K., \& Lee, J. W. (2019). Organizational Usage of Social Media for Corporate Reputation Management. Journal of Asian Finance, Economics and Business, 6(1), 231-240. http://doi. org/10.13106/jafeb.2019.vol6.no1.231

Braojos-Gomez, J., Benitez-Amado, J., \& Llorens-Montes, F. J. (2015). How do small firms learn to develop a social media competence? International Journal of Information Management, 35(4), 443-458. https://doi.org/10.1016/j. ijinfomgt.2015.04.003

Cao, Y., Ajjan, H., Hong, P., \& Le, T. (2018). Using social media for competitive business outcomes. Journal of Advances in Management Research, 15(2), 211-235. https://doi.org/10.1108/ JAMR-05-2017-0060

Cesaroni, F. M., \& Consoli, D. (2015). Are small businesses really able to take advantage of social media? Electronic Journal of Knowledge Management, 13(4), 257-268.

Chatterjee, S., \& Kar, A. K. (2020). Why do small and medium enterprises use social media marketing and what is the impact: Empirical insights from India. International Journal of Information Management, 53, 102103. https://doi. org/10.1016/j.ijinfomgt.2020.102103

Cohen, J. (1988). Statistical Power Analysis for the Behavioral Sciences (2nd ed.). Hillsdale, NJ: Lawrence Erlbaum Associates.

Das, S., Kundu, A., \& Bhattacharya, A. (2020). Technology Adaptation and Survival of SMEs: A Longitudinal Study of Developing Countries. Technology Innovation Management Review, 10(6), 64-72. http://doi.org/10.22215/timreview/1369

DiMaggio, P. J., \& Powell, W. W. (1983). The iron cage revisited: Institutional isomorphism and collective rationality in organizational fields. American Sociological Review, 48(2), 147-160. DOI: $10.2307 / 2095101$

Dutot, V., \& Bergeron, F. (2016). From strategic orientation to social media orientation. Journal of Small Business and Enterprise Development, 23(4), 1165-1190. https://doi.org/10.1108/ JSBED-11-2015-0160

Fornell, C., \& Larcker, D. F. (1981). Evaluating structural equation models with unobservable variables and measurement error. Journal of Marketing Research, 18(1), 39-50.

Garg, P., Gupta, B., Dzever, S., Sivarajah, U., \& Kumar, V. (2020). Examining the relationship between social media analytics practices and business performance in the Indian retail and IT industries: The mediation role of customer engagement. International Journal of Information Management, 52, 102069. https://doi.org/10.1016/j.ijinfomgt.2020.102069

Hair, J. F., Black, W., Babin, B., \& Anderson, R. (2010). Multivariate data analysis. Upper Saddle River, NJ: Pearson Higher Education.

Hair, J. F., Ringle, C. M., \& Sarstedt, M. (2011). PLS-SEM: Indeed a silver bullet. Journal of Marketing theory and Practice, 19(2), 139-152. https://doi.org/10.2753/MTP1069-6679190202

Henderson, D., Sheetz, S. D., \& Trinkle, B. S. (2012). The determinants of inter-organizational and internal in-house adoption of XBRL: A structural equation model. International Journal of Accounting Information Systems, 13(2), 109-140. https://doi.org/10.1016/j.accinf.2012.02.001

Henseler, J., Ringle, C. M., \& Sinkovics, R. R. (2009). The use of partial least squares path modeling in international marketing. In: New challenges to international marketing. Bingley, UK: Emerald Group Publishing Limited.

Hu, L. T., \& Bentler, P. M. (1999). Cutoff criteria for fit indexes in covariance structure analysis: Conventional criteria versus new alternatives. Structural Equation Modeling: A Multidisciplinary Journal, 6(1), 1-55.

Khan, M. A. S., Du Jianguo, A. M., Saleem, S., Boamah, K. B., Javed, U., \& Usman, M. (2019). Rejuvenating the concept of work alienation through job demands-resources model and examining its relationship with emotional exhaustion and explorative and exploitative learning. Psychology Research and Behavior Management, 12, 931. doi:10.2147/PRBM.S204193

Kizgin, H., Dey, B. L., Dwivedi, Y. K., Hughes, L., Jamal, A., Jones, P., . . Richard, M.-O. (2020). The impact of social media on consumer acculturation: Current challenges, opportunities, and an agenda for research and practice. International Journal of Information Management, 51, 102026. https://doi. org/10.1016/j.ijinfomgt.2019.10.011

Lee, J. W., Becker, K., \& Potluri, R. M. (2016). Antecedents of Corporate Adoption of Social Media and the Role of the Technology Acceptance Model in the Path. Journal of Asian Finance, Economics and Business, 3(2), 67-76. https://doi. org/10.13106/jafeb.2016.vol3.no2.67.

Lee, J. W., \& Kwag, M. (2017). Corporate Marketing Strategy Using Social Media: A Case Study of the Ritz-Carlton Seoul. 
Journal of Asian Finance, Economics and Business, 4(1), 79-86. http://dx.doi.org/10.13106/jafeb.2017.vol4.no1.79

Li, C., Ahmed, N., Qalati, S. A., Khan, A., \& Naz, S. (2020). Role of Business Incubators as a Tool for Entrepreneurship Development: The Mediating and Moderating Role of Business Start-Up and Government Regulations. Sustainability, 12(5), 1822. https://www.mdpi.com/2071-1050/12/5/1822

Maduku, D. K., Mpinganjira, M., \& Duh, H. (2016). Understanding mobile marketing adoption intention by South African SMEs: A multi-perspective framework. International Journal of Information Management, 36(5), 711-723. https://doi. org/10.1016/j.ijinfomgt.2016.04.018

Muafi, M. (2020). A Nexus among Strategic Orientation, Social Network, Knowledge Sharing, Organizational Innovation, and MSMEs Performance. Journal of Asian Finance, Economics and Business, 7(6), 327-338. https://doi.org/10.13106/ jafeb.2020.vol7.no6.327

Nguyen, X. T. (2018). The Impact of Hallyu 4.0 and Social Media on Korean Products Purchase Decision of Generation C in Vietnam. Journal of Asian Finance, Economics and Business, 5(3), 81-93. http://doi.org/10.13106/jafeb.2018.vol5.no3.81

Nguyen, X. T., \& Luu, Q. K. (2020). Factors Affecting Adoption of Industry 4.0 by Small- and Medium-Sized Enterprises: A Case in Ho Chi Minh City, Vietnam. Journal of Asian Finance, Economics and Business, 7(6), 255-264. https://doi. org/10.13106/jafeb.2020.vol7.no6.255

Nunnally, J. C. (1978). An overview of psychological measurement. In: Clinical diagnosis of mental disorders (pp. 97-146). Boston, MA: Springer.

Olanrewaju, A.-S. T., Hossain, M. A., Whiteside, N., \& Mercieca, P. (2020). Social media and entrepreneurship research: A literature review. International Journal of Information Management, 50, 90-110. https://doi.org/10.1016/j.ijinfomgt.2019.05.011

Parveen, F., Jaafar, N. I., \& Ainin, S. (2016). Social media's impact on organizational performance and entrepreneurial orientation in organizations. Management Decision, 54(9), 2208-2234. https://doi.org/10.1108/MD-08-2015-0336

Pee, L. G. (2018). Affordances for sharing domain-specific and complex knowledge on enterprise social media. International
Journal of Information Management, 43, 25-37. https://doi. org/10.1016/j.ijinfomgt.2018.05.006

Potluri, R. M., \& Vajjhala, N. R. (2018). A Study on Application of Web 3.0 Technologies in Small and Medium Enterprises of India. Journal of Asian Finance, Economics and Business, 5(2), 73-79. https://doi.org/10.13106/jafeb.2018.vol5.no2.73

Qalati, S. A., Li, W., Mirani, S. H., Sohu, J. M., Hussain, R. Y., \& Ahmed, N. (2020). The Antecedents of Green Consumer Behavior the Mediating Role of Brand Image in the Cosmetic Industry. Sukkur IBA Journal of Management and Business, 17(1), 19-39. doi:10.30537/sijmb.v7i1.527

Tajudeen, F. P., Jaafar, N. I., \& Ainin, S. (2018). Understanding the impact of social media usage among organizations. Information \& Management, 55(3), 308-321. https://doi.org/10.1016/j. im.2017.08.004

Tian, H., Iqbal, S., Akhtar, S., Qalati, S. A., Anwar, F., \& Khan, M. A. S. (2020). The Impact of Transformational Leadership on Employee Retention: Mediation and Moderation Through Organizational Citizenship Behavior and Communication. Frontiers in Psychology, 11(314). doi:10.3389/fpsyg.2020.00314

Wamba, S. F., Bhattacharya, M., Trinchera, L., \& Ngai, E. W. (2017). Role of intrinsic and extrinsic factors in user social media acceptance within workspace: Assessing unobserved heterogeneity. International Journal of Information Management, 37(2), 1-13. https://doi.org/10.1016/j.ijinfomgt.2016.11.004

Wong, K. K.-K. (2013). Partial least squares structural equation modeling (PLS-SEM) techniques using SmartPLS. Marketing Bulletin, 24(1), 1-32.

Wong, L.-W., Leong, L.-Y., Hew, J.-J., Tan, G. W.-H., \& Ooi, K.-B. (2020). Time to seize the digital evolution: Adoption of blockchain in operations and supply chain management among Malaysian SMEs. International Journal of Information Management, 52, 101997 . https://doi.org/10.1016/j. ijinfomgt.2019.08.005

Zieba, M., Bolisani, E., \& Scarso, E. (2016). Emergent approach to knowledge management by small companies: multiple casestudy research. Journal of Knowledge Management, 20(2), 292-307. https://doi.org/10.1108/JKM-07-2015-0271 